Atmos. Chem. Phys., 18, 14925-14937, 2018

https://doi.org/10.5194/acp-18-14925-2018

(C) Author(s) 2018. This work is distributed under

the Creative Commons Attribution 4.0 License.

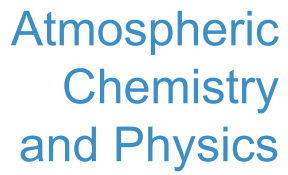

(c) (P)

\title{
Measured particle water uptake enhanced by co-condensing vapours
}

\author{
Dawei Hu, David Topping, and Gordon McFiggans \\ School of Earth and Environmental Sciences, University of Manchester, Manchester, UK \\ Correspondence: Gordon McFiggans (g.mcfiggans@manchester.ac.uk) \\ Received: 11 June 2018 - Discussion started: 26 June 2018 \\ Revised: 25 September 2018 - Accepted: 27 September 2018 - Published: 17 October 2018
}

\begin{abstract}
Co-condensation of inorganic or organic vapours on growing droplets could significantly enhance both cloud condensation nucleus $(\mathrm{CCN})$ and cloud droplet number concentration, thereby influencing cloud albedo and climate. Until now, there has been very few direct observational evidence of this process. We have measured the growth of inorganic salt particles exposed to both water and organic vapours at $291.15 \mathrm{~K}$ in the laboratory, showing that co-condensation of the organic vapours significantly enhances water uptake of aerosols. After exposure to water and propylene glycol vapours, ammonium sulfate particles grew much more than any previously measured particles, inorganic or organic, at the same relative humidity (RH). The maximum equivalent hygroscopicity parameter, $\kappa$, was observed to reach up to 2.64 , very much higher than values $(0.1<\kappa<0.9)$ measured for atmospheric particulate matter using conventional instrumentation, which may be blind to this effect. Under a continuously replenishing organic vapour field, the particles never reached equilibrium owing to the presence of the involatile solute and were observed to continuously grow with increasing exposure time, in agreement with model simulations. Cocondensation of butylene glycol (which has similar volatility but, at $a_{\mathrm{w}}=0.9$, a higher $S_{\text {org }}$ than propylene glycol in our system) and tri-ethylene glycol (which has lower volatility and, at $a_{\mathrm{w}}=0.9$, lower $S_{\text {org }}$ than propylene glycol in our system) vapours was additionally measured in this study. The maximum equivalent hygroscopicity parameter, $\kappa$, reached as high as 8.48 for ammonium sulfate particles exposed to water and tri-ethylene glycol vapours at $90 \% \mathrm{RH}$. This enhancement of particle water uptake through co-condensation of vapours constitutes the direct measurement of this process, which may substantially influence cloud droplet formation in the atmosphere. In addition, the model simulations for exposure to co-condensing butylene glycol and tri-ethylene glycol vapours with water show that there are factors other than $S_{\text {org }}$
\end{abstract}

which influence the co-condensation of semi-volatile organic compounds (SVOCs) that are as yet not understood.

\section{Introduction}

Clouds have a profound influence on weather and climate. According to the Intergovernmental Panel on Climate Change (IPCC), the impacts of aerosols on clouds are one of the largest uncertainties in estimates of global radiative forcing (Denman et al., 2007). Particle size, composition, mixing states, and various derived properties such as hygroscopicity are the main factors to determine if particles can act as a cloud condensation nuclei (CCN) and then form the cloud droplets under atmospheric water saturation ratio (McFiggans et al., 2006; Dusek et al., 2006; Topping and McFiggans, 2012).

The formation of cloud droplets by the condensation of water vapours on particles can be predicted by traditional Köhler theory (Köhler, 1936). The theory, in its original unmodified form, was designed for particles comprising involatile components in the presence of a single supersaturated vapour. In addition to semi-volatile inorganic gases such as ammonia and nitric acid, there are many organic compounds of varying volatility (McFiggans et al., 2010) in the atmosphere, which, if they were to influence water uptake, would substantially affect cloud properties (Topping et al., 2013). Kulmala et al. (1993) first suggested that cocondensation of atmospheric $\mathrm{HNO}_{3}$ could alter the activation and growth of cloud CCN significantly and this was extended to more comprehensively consider more complex inorganic systems including $\mathrm{NH}_{3}$ (Hegg, 2000; Xue and Feingold, 2004; Laaksonen et al., 1998; Romakkaniemi et al., 2005). Recently, co-condensation of organic vapours on the growing droplets was also suggested to substantially enhance 
both $\mathrm{CCN}$ and cloud droplet number concentration, thereby influencing cloud albedo. The cooling tendency from a net influence on cloud albedo associated with the predicted enhancement in droplet number was estimated to be of the order of $1 \mathrm{~W} \mathrm{~m}^{-2}$. However, all of these studies were solely theoretical. Current weather, climate, air quality, or Earth system models do not include this process. There has been very little previous direct measurement evidence for this process in either inorganic (Rudolf et al., 2001) or organic (Rudolf et al., 1991) systems, and existing instrumentation that is used to inform and challenge models has not been designed to be sensitive to this effect.

To directly probe co-condensation, we consider the case of a particle comprising a single involatile water-soluble solute. Exposure to an environment with a constant saturation ratio of water and semi-volatile organic vapours $\left(S_{\mathrm{w}}=\right.$ relative humidity, RH, and $S_{\text {org }}$, respectively) should lead to condensation of both vapours towards an equilibrium particle composition and size. However, the ability of the particle to reach such a state will be inhibited by the presence of the original involatile solute. This will result in the condensed phase activity of the involatile component persisting above the vapour phase saturation ratio, and condensed phase activities of the semi-volatile components below their saturation ratios. Water and organic vapour will therefore continue to condense and the droplets will continuously grow by the same process that has been hypothesized to lead to clouds of stable supermicron droplets below water supersaturation (Kulmala et al., 1997).

In this study, ammonium sulfate, a representative atmospheric electrolyte, was chosen as the involatile solute. Propylene glycol (PG), butylene glycol (BG), and triethylene glycol (TEG) were selected as the semi-volatile organic compounds since they are completely miscible with water across their concentration ranges, thereby reducing the likelihood of abrupt changes in ideality associated with phase transitions. These compounds were deliberately chosen to avoid complicating factors such as immiscibility and solubility limitation that would confound straightforward quantitative interpretation. Such cases may show less dramatic influences of co-condensation; nevertheless. they would still only enhance water uptake and never reduce it below the case where there was no co-condensation. It is not the intention to fully explore all possible atmospheric behaviours, which must remain the scope of future work.

\section{Methods}

\subsection{Experimental setup}

\subsubsection{Sub-saturation ratio hygroscopic growth measurement}

Figure 1 shows the experimental setup for investigating the influence of co-condensation of organic vapours on the water uptake of $\left(\mathrm{NH}_{4}\right)_{2} \mathrm{SO}_{4}$ particles. The configuration is based on a modification of the self-made hygroscopicity tandem differential mobility analyser (HTDMA) system at the University of Manchester (Good et al., 2010). Briefly, polydisperse $\left(\mathrm{NH}_{4}\right)_{2} \mathrm{SO}_{4}$ particles produced by an atomizer are dehydrated to $\sim 10 \%$ RH through a Nafion drier and then neutralized with a ${ }^{90} \mathrm{Sr}$ diffusion charger before size-selected $\left(D_{0}\right)$ by the first DMA (DMA-1; Brechtel Manufacturing Inc., USA). Quasi-monodisperse particles exiting DMA-1 are subsequently exposed to water and organic vapours in a glass reactor containing an organic-water solution with water activity at 0.9 . The particles are thus grown in a continually replenished $\mathrm{RH}$ of $90 \%$ and a certain $S_{\text {org }}$ (depends on non-ideality). The particle diameter $\left(D_{\mathrm{p}}\right)$ is measured using a second DMA (DMA-2; Brechtel Manufacturing Inc., USA) before detection using a condensation particle counter (CPC; model 3786, TSI Inc., USA). The hygroscopic growth factor (GF), defined as the ratio of the processed particle diameter $\left(D_{\mathrm{p}}\right)$ over the initial dry particle diameter $\left(D_{0}\right)$, was obtained through the inversion of scanning DMA-2 data by the TDMAInv software (Gysel et al., 2009). The pure component properties of the semi-volatile PG, BG, and TEG used in their aqueous solutions as the working fluids in our experiments are summarized in Table 1.

During the experiment, both DMAs and the glass reactor were temperature controlled and held at $18^{\circ} \mathrm{C}$ in a thermostatic box with a temperature fluctuation smaller than $0.2 \mathrm{~K}$. $\mathrm{RH}$, temperature, and flows in the instrument were monitored at several locations, and the $\mathrm{RH}$ and temperature measured at the sample outlet of DMA-2 were used for subsequent calculation. The dew point sensor was found to be unsuitable for this study since the co-condensation of PG and water vapour on the chilled mirror surface led to overestimation of RH. All RH sensors were capacitance sensors, and were found to be uninfluenced by the organic vapours in our experiment. To investigate the exposure time effects on the water uptake of $\left(\mathrm{NH}_{4}\right)_{2} \mathrm{SO}_{4}$ particles, $0.5,2$, and $4 \mathrm{~m}$ long glass reactors (I.D. $=2.4 \mathrm{~cm}$ ) with 50,200 , and $400 \mathrm{~mL}$ of prepared organic-water solutions were studied separately; the corresponding residence time of particles in each glass reactor being 23.5, 94, and $188 \mathrm{~s}$, respectively. Based on the sample flow rate $\left(0.45 \mathrm{~L} \mathrm{~min}^{-1}\right)$ and glass cell dimensions, the calculated Reynolds number is less than 100, enabling the assumption of laminar flow. 


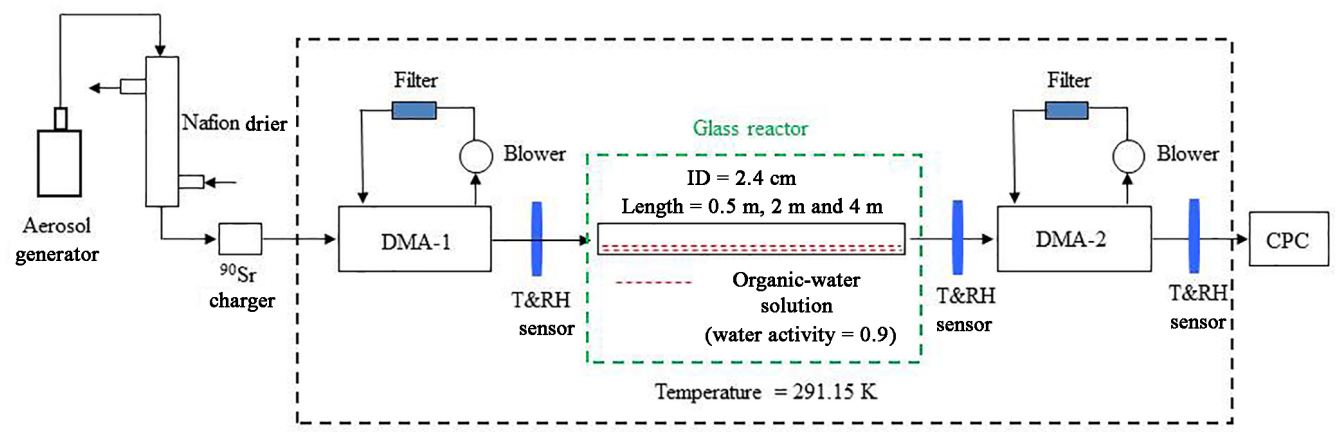

Figure 1. Schematic diagram of the experimental configuration.

Table 1. Parameters of propylene glycol, butylene glycol, and tri-ethylene glycol.

\begin{tabular}{lllrrr}
\hline Organics & $\begin{array}{l}\text { Molecular } \\
\text { formula }\end{array}$ & $\begin{array}{l}\text { Solubility } \\
\text { in water } \\
\left(\mu \mathrm{g} \mathrm{m}^{-3}\right)\end{array}$ & $\begin{array}{r}\text { Activity with } \\
a_{\mathrm{w}}=0.9\end{array}$ & $\begin{array}{r}\log _{10}\left(\mathrm{C}^{*}\right) \\
@ 25^{\circ} \mathrm{C}\end{array}$ & $\begin{array}{r}\Delta H \text { (Vap) } \\
\left(\mathrm{KJ} \mathrm{mole}^{-1}\right)\end{array}$ \\
\hline Propylene Glycol & $\mathrm{C}_{3} \mathrm{H}_{8} \mathrm{O}_{2}$ & Miscible & 0.1 & 5.71 & 61.30 \\
Butylene Glycol & $\mathrm{C}_{4} \mathrm{H}_{10} \mathrm{O}_{2}$ & Miscible & 0.164 & 5.64 & 59.91 \\
Tri-ethylene Glycol & $\mathrm{C}_{6} \mathrm{H}_{14} \mathrm{O}_{4}$ & Miscible & 0.026 & 3.27 & 90.67 \\
\hline
\end{tabular}

\subsubsection{Droplet activation measurement above water saturation}

A continuous-flow stream-wise thermal gradient diffusion chamber and cloud condensation nucleus counter (CFSTGDC CCNc, DMT) was used to attempt to measure the droplet activation of $\left(\mathrm{NH}_{4}\right)_{2} \mathrm{SO}_{4}$ particles in both water and organic vapours. The reactor outflow containing the grown $\left(\mathrm{NH}_{4}\right)_{2} \mathrm{SO}_{4}$ particles was split between the $\mathrm{CCNc}$ and a CPC (3775, TSI) instead of DMA-2 in Fig. 1. By stepping through different dry sizes in DMA-1, the activation diameter $\left(D_{50}\right)$ of $\left(\mathrm{NH}_{4}\right)_{2} \mathrm{SO}_{4}$ particles at a given water supersaturation (SS) was determined as the diameter at which $50 \%$ of the particle number concentration measured by the $\mathrm{CPC}$ were measured to be activated in the $\mathrm{CCNc}$.

\subsection{Instrument calibration and characterization}

\subsubsection{Calibration and certification of the HTDMA system}

Before the experiment, DMA-1 was calibrated with certified polystyrene latex spheres. The offset in the size measurement of the two DMAs was determined with dry $\left(\mathrm{NH}_{4}\right)_{2} \mathrm{SO}_{4}$ particles by using an empty glass reactor in the system to maintain the dry environment of DMA-2. In addition, to verify the performance of the modified H-TDMA system, GFs of $\left(\mathrm{NH}_{4}\right)_{2} \mathrm{SO}_{4}$ particles were measured after passing through the headspace in the glass reactor containing the $\mathrm{NaCl}$-water solution with the water activity at 0.9 . Since $\mathrm{NaCl}$ is involatile, the growth of $\left(\mathrm{NH}_{4}\right)_{2} \mathrm{SO}_{4}$ particles resulted solely

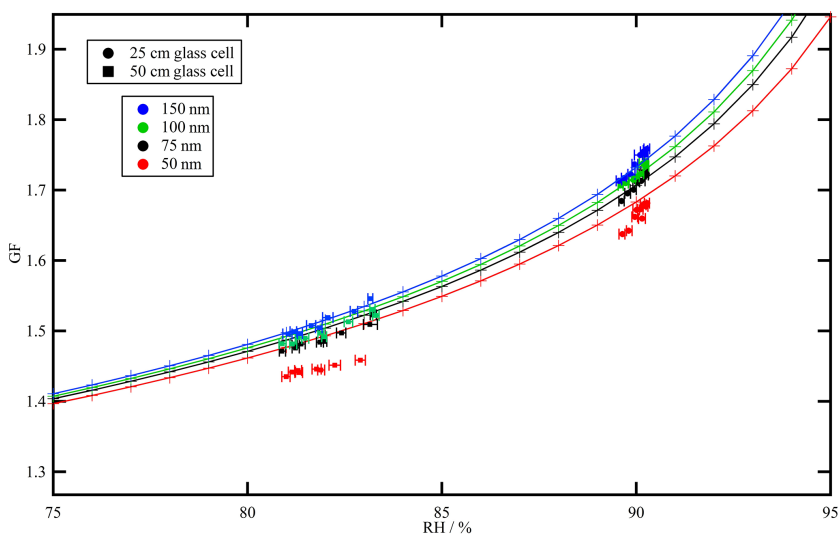

Figure 2. $\mathrm{GF}$ of $\left(\mathrm{NH}_{4}\right)_{2} \mathrm{SO}_{4}$ particles after transit through the 0.25 and $0.5 \mathrm{~m}$ glass reactors containing $\mathrm{NaCl}-\mathrm{H}_{2} \mathrm{O}$ solution with the water activity at 0.9 .

from the uptake of water vapour. As shown in Fig. 2, for the $0.5 \mathrm{~m}$ glass cell with $50 \mathrm{~mL} \mathrm{NaCl}$-water solution (approximate average residence time $=23.5 \mathrm{~s}$ ), the measured $\mathrm{RH}$ in the DMA-2 sample line is $90 \pm 0.3 \%$, exactly corresponding to the equilibrium $\mathrm{RH}(90 \%)$ with the prepared $\mathrm{NaCl}-$ water solution. For a $0.25 \mathrm{~m}$ glass cell with $25 \mathrm{~mL} \mathrm{NaCl}$ water solution (residence time $=11.7 \mathrm{~s}$ ), the measured $\mathrm{RH}$ was found to vary between $81 \%$ and $83 \%$, lower than the expected value of $90 \%$. This demonstrates that a $0.5 \mathrm{~m}$ glass cell is sufficiently long to allow dried $\left(\mathrm{NH}_{4}\right)_{2} \mathrm{SO}_{4}$ particles to reach the equilibrium $\mathrm{RH}$ ( $90 \%$ in this study) with the prepared solution, whilst a $0.25 \mathrm{~m}$ reactor is not. Thus, the 
minimum length of the glass reactor used in this study is $0.5 \mathrm{~m}$, sufficient to expose the particles to their equilibrium RH of $90 \%$. For both the 0.25 and $0.5 \mathrm{~cm}$ glass reactors, the measured GFs of $\left(\mathrm{NH}_{4}\right)_{2} \mathrm{SO}_{4}$ particles agree well with the Aerosol Diameter Dependent Equilibrium Model (ADDEM) calculations (http://umansysprop.seaes.manchester.ac.uk/) at the corresponding RH, indicating the good performance of the modified H-TDMA system. Similarly good agreement is achieved in the longer reactors.

\subsubsection{Calibration of the CCN counter}

Before the experiment, the $\mathrm{CCN}$ counter was calibrated with $\left(\mathrm{NH}_{4}\right)_{2} \mathrm{SO}_{4}$ particles. Briefly, $\left(\mathrm{NH}_{4}\right)_{2} \mathrm{SO}_{4}$ particles were generated in the same manner as for the HTDMA calibrations. Nafion-dried $\left(\mathrm{NH}_{4}\right)_{2} \mathrm{SO}_{4}$ particles were neutralized using a ${ }^{90} \mathrm{Sr}$ diffusion charger, and size selected by a DMA before splitting the flow between the CCNc and a CPC (3775, TSI). The DMA voltage was stepped to select each size and kept constant for $20 \mathrm{~s}$, using data in the last $10 \mathrm{~s}$ to calculate the ratio of $\mathrm{N}_{C C N} / \mathrm{N}_{\mathrm{CPC}}$. The activation diameter $\left(D_{50}\right)$ of $\left(\mathrm{NH}_{4}\right)_{2} \mathrm{SO}_{4}$ particles at a given water SS was determined when the ratio of $\mathrm{N}_{C C N} / \mathrm{N}_{C P C}=0.5$. The theoretical $\mathrm{S} S_{\text {critical }}$ corresponding to the measured $D_{50}$ from the ADDEM model was used to calibrate the SS in the CCNc.

\subsubsection{The effect of the time for the system to reach the steady state}

Before commencing each experiment, the system was required to have reached steady state, such that vapour losses to, and outgassing from, the tubing, reactor and inside of the DMA-2 led to a stable measurement of GF. Figure 3 illustrates the effect of the time to reach the steady state of the system. For the $0.5 \mathrm{~m}$ glass reactor with $50 \mathrm{~mL}$ aqueous PG solution, after the system has continuously run for $70 \mathrm{~h}$, the measured GF of $\left(\mathrm{NH}_{4}\right)_{2} \mathrm{SO}_{4}$ particles after passing through the glass reactor becomes stable within the experimental uncertainty, i.e. the system reached the steady state. Similar behaviour was observed and duplicated for all reactor lengths and the particle GFs in this study are only reported after the system has reached steady state for all reactor lengths. This extended stabilization period is the most challenging practical limitation of the system.

\subsection{Model simulation}

The Aerosol-Cloud-Precipitation Interactions Model (ACPIM) was used to simulate the growth of monodisperse $\left(\mathrm{NH}_{4}\right)_{2} \mathrm{SO}_{4}$ particles with water and organic vapours using the same numerical basis described in Topping et al. (2013). ACPIM is a numerical model of aerosol, cloud, and precipitation interactions that simulates the growth of particles of defined arbitrary size or composition as they compete with available vapours to act as $\mathrm{CCN}$ in cloud droplet formation or ice nuclei in ice crystal formation under evolving ambient

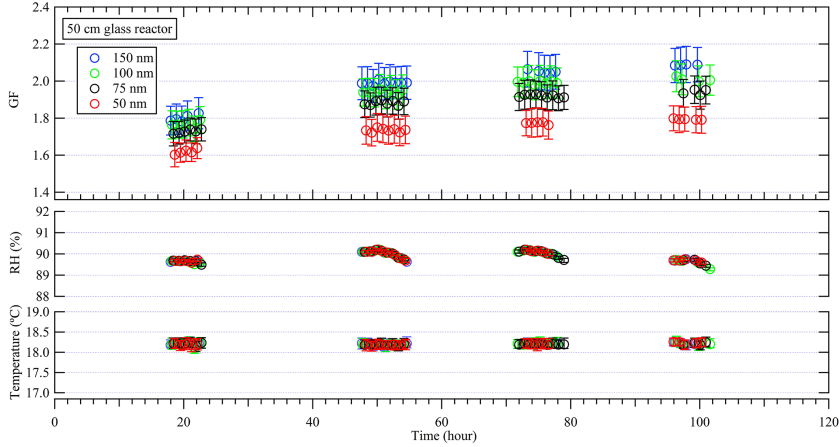

Figure 3. Time taken to achieve stable measurements in the HTDMA system. Steady state was only attained after several days, after which the GF remained constant for each organic system.

environmental conditions. In its usual configuration, ACPIM solves four coupled ordinary differential equations for the water and organic vapour mass mixing ratio, pressure, temperature, and height of an air parcel rising through the moist atmosphere in hydrostatic balance. The model was simplified to run at constant pressure and laboratory temperature, to treat an initially monodisperse particle population, and only one condensable organic vapour in addition to water. The mass of water and organic compounds condensing to the particles by virtue of the difference of vapour pressure between the particle surface and the surrounding air was followed in the simulation. The dried sample flow does not instantaneously reach the water and organic vapour saturation ratios on entry to the reactor but mixing ratios of both will increase towards the equilibrium value with exposure time. The glass reactor walls compete with the growing particles for both components, but the vapours are continually replenished from the solution bath.

\section{Results and discussion}

\subsection{Direct measurements of particle growth in co-condensing vapours}

\subsubsection{Hygroscopic growth measurements below water saturation}

Figure 4a shows the measured and modelled growth of monodisperse $\left(\mathrm{NH}_{4}\right)_{2} \mathrm{SO}_{4}$ particles in the presence of water and $\mathrm{PG}$ vapours and Fig. $4 \mathrm{~b}$ illustrates the difference in the growth of $\left(\mathrm{NH}_{4}\right)_{2} \mathrm{SO}_{4}$ particles when exposed to only water vapour or when exposed to the mixture of water and organic vapours. In the absence of organic vapours, $\left(\mathrm{NH}_{4}\right)_{2} \mathrm{SO}_{4}$ particles remain solid with increasing RH until the deliquescence RH (DRH) is reached, at which point there is a distinct and abrupt increase in diameter as the particles undergo a solid- to liquid-phase transition. Further increase in the RH leads to additional water condensation on the salt solution 


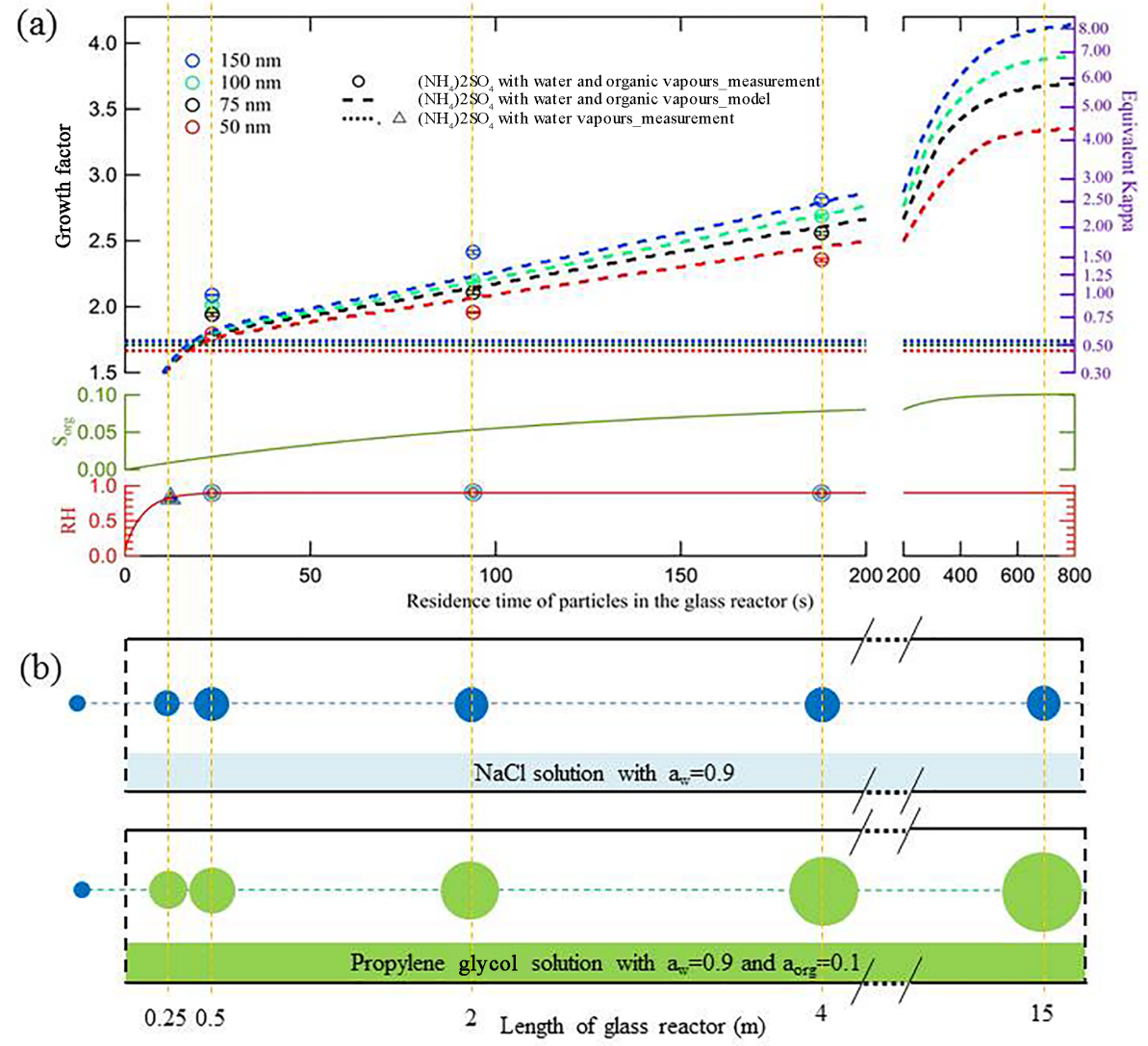

Figure 4. Growth of $\left(\mathrm{NH}_{4}\right)_{2} \mathrm{SO}_{4}$ particles exposed to water and propylene glycol, PG, vapours. (a) Measured (circle) and simulated (dash line) GFs with the residence time, the equivalent hygroscopicity (the $\kappa$ that an involatile particle would need in order to show the growth factor (GF) in the absence of co-condensing vapours) corresponding to the GF axis is presented on the right-hand axis of the top panel; the simulated $\mathrm{RH}$ and $\mathrm{S}_{\text {org }}$ profiles are presented as solid red and green lines, respectively. (b) Schematic illustration of $\left.100 \mathrm{~nm}_{(\mathrm{NH}}\right)_{2} \mathrm{SO}_{4}$ particles growth in the glass reactor, particle diameters to scale.

and the particle increases in size. When the RH reaches equilibrium, the droplet size remains constant and is not influenced by the exposure time. When the $\left(\mathrm{NH}_{4}\right)_{2} \mathrm{SO}_{4}$ particles are exposed to water and organic vapours, both condense and the particle increases in size more rapidly than in the absence of organic vapours. Condensation depends on the concentration difference between the ambient air and the surface of droplet. Each semi-volatile compound (including water) tends to simultaneously condense from the vapour phase towards particles according to its prevailing saturation ratio. The sum of the vapour saturation ratios in the reactor headspace tends towards unity above the aqueous organic solution. The sum of the activities in the particles will always be a finite amount below unity owing to the presence of the involatile $\left(\mathrm{NH}_{4}\right)_{2} \mathrm{SO}_{4}$. This leads to the continuous existence of a driver towards condensational growth of the particles, such that the droplets cannot achieve equilibrium with surrounding organic vapour and water activities in the time allowed in the continuously replenishing vapour field. Owing to the presence of $\left(\mathrm{NH}_{4}\right)_{2} \mathrm{SO}_{4}$ solute in the droplet solution, the droplet will continuously grow throughout their period of exposure to the vapours.

Figure 4 shows that the measured GF of $\left(\mathrm{NH}_{4}\right)_{2} \mathrm{SO}_{4}$ particles increased significantly more than at the same $\mathrm{RH}$ where no condensable organic vapours are present (dotted line). After exposure to propylene glycol and water vapour for $188 \mathrm{~s}$, dry $150 \mathrm{~nm}\left(\mathrm{NH}_{4}\right)_{2} \mathrm{SO}_{4}$ particles increase in diameter to $422 \mathrm{~nm}(\mathrm{GF}=2.81), 160 \mathrm{~nm}$ greater than when exposed to water vapour only. This clearly shows that co-condensation of semi-volatile organic vapours greatly increases the water uptake of aerosol droplets, to such an extent that the measured GF at $90 \% \mathrm{RH}$ is greater than has been measured even for the most hygroscopic inorganic salts in the absence of organic vapours. In addition, the GF of monodisperse $\left(\mathrm{NH}_{4}\right)_{2} \mathrm{SO}_{4}$ particles was observed to increase with the length of reactor (and hence exposure time at a given flow rate). For example, $150 \mathrm{~nm}$ dry particles were measured at 314,362 , and $422 \mathrm{~nm}$ with reactor lengths of $0.5,2$, and $4 \mathrm{~m}$ (and exposure times of 23.5, 94, and $188 \mathrm{~s}$ ), respectively. These GF values would be equivalent to values of the hygroscopicity parameter, $\kappa$, of $1.00,1.46$, and 2.64 if the particles 


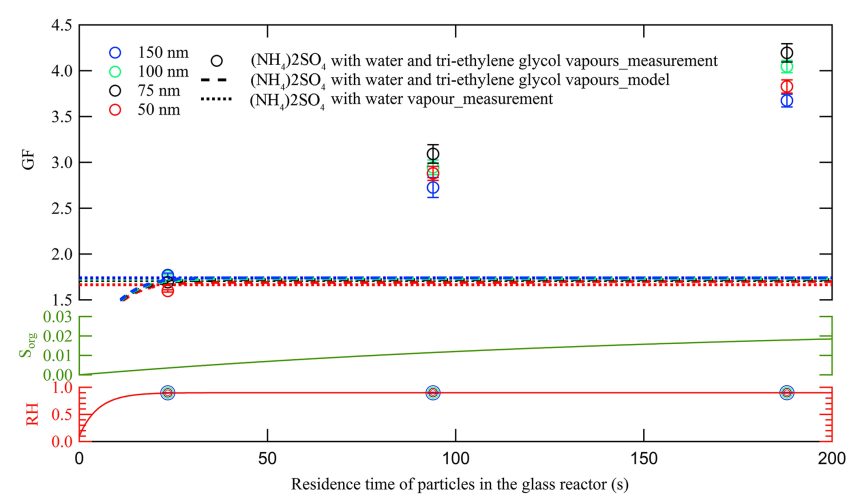

Figure 5. Measured (circle) and simulated GF (dash line) with residence time for $\left(\mathrm{NH}_{4}\right)_{2} \mathrm{SO}_{4}$ particles exposed to water and TEG vapours. The simulated RH and $S_{\text {org }}$ profiles, which following the same exponential function as the experiment with PG vapour, are presented as solid red and green lines, respectively.

were considered to comprise involatile solute. Importantly, this shows that the equivalent $\kappa$ value is dependent on the exposure time and amount of vapour so the hygroscopicity in the presence of condensable vapours cannot be defined for a particle if only the composition of the condensed material is known.

Co-condensation of semi-volatile organic compounds (SVOCs) depends directly on RH and $S_{\text {org. This is the ra- }}$ tio of the ambient partial pressure to the vapour pressure under the ambient conditions $\left(\mathrm{p} / p_{0}\right)$. Increasing the concentration difference between the ambient air and the surface of droplet will enhance co-condensation. As shown in Table $1, \mathrm{BG}\left(\log _{10}\left(\mathrm{C}^{*}\right)=5.64\right)$ has very similar volatility to $\mathrm{PG}$ $\left(\log _{10}\left(C^{*}\right)=5.71\right)$, but exhibits higher activity $a_{B G}(0.164)$ than $a_{\mathrm{PG}}(0.1)$ at the same water activity, $a_{\mathrm{w}}$, of 0.9 . According to our theoretical understanding, replacing the aqueous PG solution with BG solution in our system should increase the difference of organic concentration between the ambient air and the surface of the droplet. This should, in turn, enhance the co-condensation of water and organic vapours to the particle phase, increasing the droplet size by condensation. Contrary to this expectation, as shown in Table 2, the GF and equivalent $\kappa$ value of $\left(\mathrm{NH}_{4}\right)_{2} \mathrm{SO}_{4}$ particles exposed to the headspace above the aqueous BG solution in the $2 \mathrm{~m}$ reactor were smaller than those exposed to PG and water vapours (though clearly still higher than those exposed to water vapour alone). For $100 \mathrm{~nm}\left(\mathrm{NH}_{4}\right)_{2} \mathrm{SO}_{4}$ particles, the GF and equivalent $\kappa$ value were observed at 1.98 and 0.83 , respectively, in the former lower than the corresponding values of 2.19 and 1.11 in the latter. Possible explanations will be discussed in the Sect. 3.2.2. In contrast to BG, TEG has a lower vapour pressure (corresponding to a saturation concentration of $\left.\log _{10}\left(\mathrm{C}^{*}\right)=3.27\right)$ than PG and lower activity, $a_{\mathrm{TEG}},(0.026)$ than $a_{\mathrm{PG}}(0.1)$ in an aqueous solution of the same water activity, $a_{\mathrm{w}}$, of 0.9 . However, the GF and equiva- lent $\kappa$ value of $\left(\mathrm{NH}_{4}\right)_{2} \mathrm{SO}_{4}$ particles exposed to the 2 and $4 \mathrm{~m}$ glass reactors with the aqueous TEG solution were observed to be much greater than that with aqueous PG. As shown in Table 2 and the open circles (measured GF) in the top panel of Figure 5, the GF (and the corresponding calculated equivalent $\kappa$ value) of dry $75 \mathrm{~nm}$ particles were measured at 3.09 (3.39) and 4.19 (8.48) with reactor lengths of 2 and $4 \mathrm{~m}$ (and exposure times of 94 and $188 \mathrm{~s}$ ), respectively, much larger than the corresponding values of 2.11 (1.02) and 2.56 (2.09) for the PG experiment.

\subsubsection{Insensitivity of the $\mathrm{CCN}$ counter to co-condensation of organic vapours}

The CCN behaviour of $\left(\mathrm{NH}_{4}\right)_{2} \mathrm{SO}_{4}$ particles after exposure to PG $\left(a_{\mathrm{PG}}=0.1\right)$ and water $\left(a_{\mathrm{w}}=0.9\right)$ solution in the glass reactor was referenced to measurements made using an aqueous $\mathrm{NaCl}$ solution with $a_{\mathrm{w}}=0.9$. As shown in Fig. 6a, no clear difference of kappa and $D_{50}$ was observed and the kappa difference and $D_{50}$ difference was less than 0.05 and $3 \mathrm{~nm}$, respectively. This results from evaporation of the organic vapour in the heated column whilst the water vapour from the wetted walls condenses onto the activating droplet. The operating principle of this type of continuous flow diffusion chamber and CCN counter is to create a SS down the instrument centreline through the slower diffusion of heat than of water vapour from the heated and wetted walls. Simultaneously in our experiment, the saturation ratio $\left(p / p_{0}\right)$ of PG will decrease on moving down the centreline of the column, since its saturation vapour pressure $\left(p_{0}\right)$ increases with temperature. This would clearly favour evaporation rather than co-condensation of PG vapour. It is possible that there is an indication that the difference of kappa and $D_{50}$ may have been significant at the lowest set point SS only. Such behaviour would be consistent with the organic vapour being evaporated least with the lowest temperature difference used to create the low SS. Figure 6b presents the temperature difference and the corresponding calculated ratio of $S_{\text {org }}$ between the outlet and inlet of the $\mathrm{CCNc}$ under different $\mathrm{SS}$. Our results show that the $\mathrm{CCNc}$ is insensitive to the cocondensation of organic vapours once the $S_{\text {org }}$ (outlet) $/ S_{\text {org }}$ (inlet) ratio decreased to around 0.69 .

This result demonstrates that instruments conventionally used to measure particle water uptake will be largely insensitive to, or be unable to quantitatively access, the cocondensation effect. The same result was also observed by Romakkaniemi et al. (2014) in their investigation of the evaporation of ammonium nitrate and condensation of nitric acid inside the DMT CCN counter. Whilst humidity is controlled in such instruments, initial drying of the sample stream or heating within an instrument will likely suppress the saturation ratio of organic components by decreasing the organic component mixing ratio or raising the saturation vapour pressure, respectively. 
Table 2. Growth factor and the equivalent kappa of $\left(\mathrm{NH}_{4}\right)_{2} \mathrm{SO}_{4}$ particles exposed in propylene glycol and water, butylene glycol and water, and tri-ethylene glycol and water vapours in a $2 \mathrm{~m}$ glass reactor.

\begin{tabular}{lrrrr}
\hline & \multicolumn{4}{c}{ Growth factor (equivalent $\kappa$ value) } \\
\cline { 2 - 5 } Organics & $50 \mathrm{~nm}$ & $75 \mathrm{~nm}$ & $100 \mathrm{~nm}$ & $150 \mathrm{~nm}$ \\
\hline Propylene Glycol & $1.96(0.87)$ & $2.11(1.02)$ & $2.19(1.11)$ & $2.41(1.46)$ \\
Butylene Glycol & $1.78(0.58)$ & $1.91(0.81)$ & $1.98(0.83)$ & $2.14(1.08)$ \\
Tri-ethylene Glycol & $2.88(2.73)$ & $3.09(3.39)$ & $2.95(2.94)$ & $2.73(2.32)$ \\
\hline
\end{tabular}

(a)

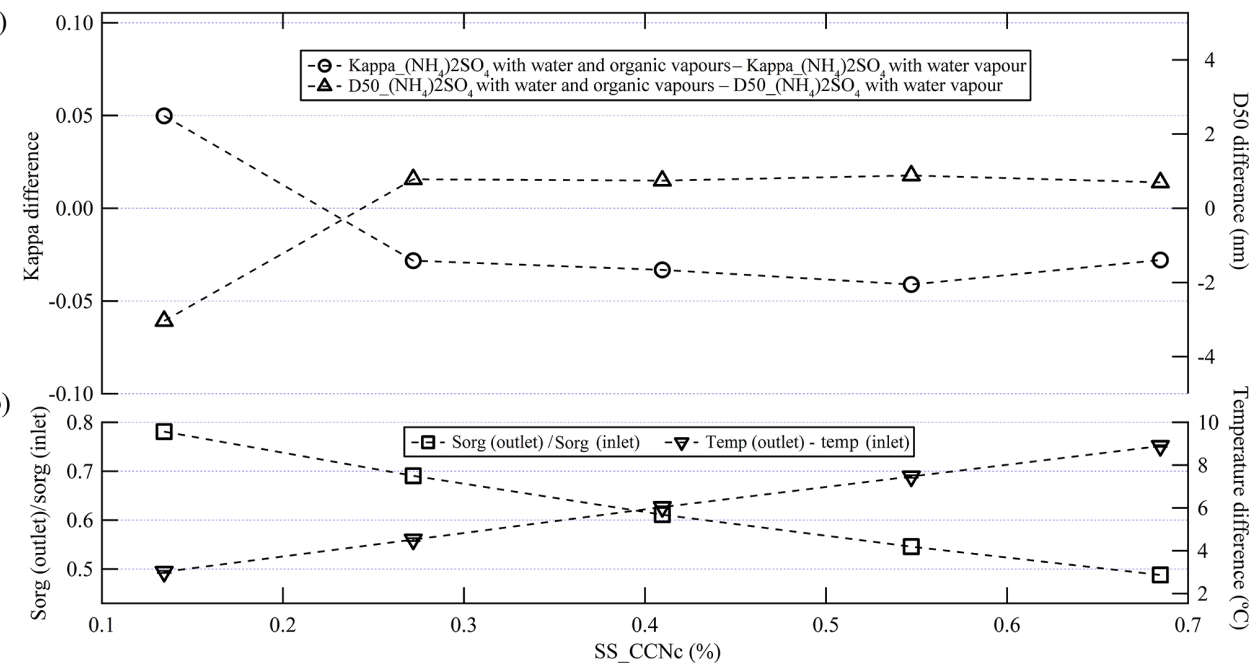

Figure 6. (a) Kappa and $D_{50}$ difference of $\left(\mathrm{NH}_{4}\right)_{2} \mathrm{SO}_{4}$ particles measured with and without organic vapours in the sample and sheath air in the CCNc, (b) Temperature difference and the corresponding calculated ratio of $S_{\text {org }}$ between outlet and inlet of the CCNc under different SS.

\subsection{Numerical model interpretation of co-condensing particle growth}

To quantitatively understand co-condensation of organic vapours to the particle droplets, we attempted to simulate the growth of monodisperse $\left(\mathrm{NH}_{4}\right)_{2} \mathrm{SO}_{4}$ particles in water and organic vapours using the Aerosol-Cloud and Precipitation Interactions Model (ACPIM; Topping et al., 2013).

\subsubsection{Monodisperse $\left(\mathrm{NH}_{4}\right)_{2} \mathrm{SO}_{4}$ particle growth in water plus propylene glycol (PG) vapours}

In the ACPIM simulations, the RH (Fig. 4a, red line) and $S_{\text {org }}$ (green line) increase with the residence time after the dry $\left(\mathrm{NH}_{4}\right)_{2} \mathrm{SO}_{4}$ particles enter into the glass reactor. The $\mathrm{RH}$ profile is constrained by the experimental data which shows that particles reach their equilibrium size at $90 \% \mathrm{RH}$ within the $0.5 \mathrm{~m}$ reactor filled with a $\mathrm{NaCl}-$ water solution. The $S_{\text {org }}$ profile was used to optimize the fit between simulated and measured GFs at each reactor length. As shown in Fig. 4a, the $\mathrm{RH}$ rapidly reaches equilibrium $(\sim 20 \mathrm{~s})$ in the glass reactor, while $S_{\text {org }}$ needs longer ( $\sim 700 \mathrm{~s}$ ) (corresponding to $15 \mathrm{~m}$ glass reactor). This is to be expected, since water is more volatile than PG, and water vapour lost to the walls will be more rapidly replenished from the solution than the PG vapours. The best fit simulation indicates that the steady state between wall loss and replenishment from the solution bath does not allow the system to reach its equilibrium $S_{\text {org }}$ in the maximum available exposure time in our experimental configuration. This increase in $S_{\text {org }}$ might therefore be expected to lead to an increasing GF with the residence time as we observe. The $\left(\mathrm{NH}_{4}\right)_{2} \mathrm{SO}_{4}$ present in solution would effectively preclude equilibration (at least delaying it until the inorganic mole fraction was negligible) and the concentration difference between the surrounding air and the surface of droplet will drive water and organic vapours to continuously condense on the droplets. This is illustrated by the continuous increase in the simulated GF beyond the point at which the vapour reaches its equilibrium $S_{\text {org }}$ (residence time $>700$ s). The GF of larger particles is both measured and simulated to be larger than small ones, reflecting the Kelvin term size dependence of the equilibrium water and PG content of the particles. 


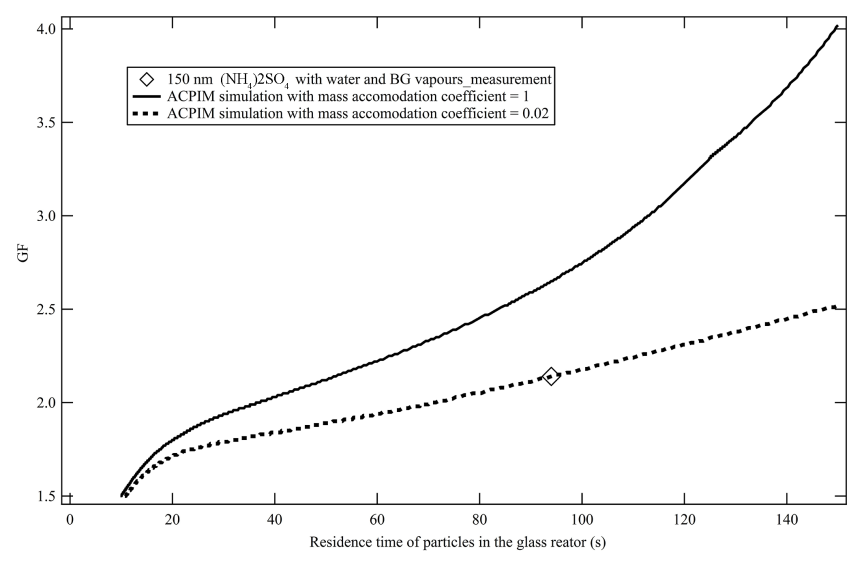

Figure 7. Measured and simulated GF with residence time for $\left(\mathrm{NH}_{4}\right)_{2} \mathrm{SO}_{4}$ particles exposed to water and BG vapours.

\subsubsection{Monodisperse $\left(\mathrm{NH}_{4}\right)_{2} \mathrm{SO}_{4}$ particles growth in water plus butylene glycol (BG) and water plus tri-ethylene glycol (TEG) vapours}

The ACPIM-simulated GFs with residence time for $\left(\mathrm{NH}_{4}\right)_{2} \mathrm{SO}_{4}$ particles in water plus $\mathrm{BG}$ or TEG vapour are presented in Figs. 7 and 5, respectively. For both simulations, the RH and $S_{\text {org }}$ profile used the same exponential function as the previous simulation for PG, but the final $S_{\text {org }}$ values were changed to 0.164 and 0.026 (see Table 1), the corresponding solute activities of BG and TEG, respectively, with the water activity, $a_{\mathrm{w}}$, of 0.9 . Since the evaporation rate is controlled by the component vapour pressure (and since BG has comparable volatility to $\mathrm{PG}$ ), using the same exponential function for RH and $S_{\text {org }}$ should be reasonable. As shown in Fig. 7, the simulated GF using aqueous BG (solid black line) was greater than that using the aqueous PG solution (blue dash line in Fig. 4). This results from the higher $S_{\text {org }}$ of BG, producing the larger difference in organic concentration between the ambient air and the surface of droplet, enhancing the co-condensation of water and organic vapours, leading to a larger droplet. This contrasts with a measured GF (2.14) of $150 \mathrm{~nm}\left(\mathrm{NH}_{4}\right)_{2} \mathrm{SO}_{4}$ after transit through the $2 \mathrm{~m}$ glass reactor containing aqueous BG solution (much lower than the predicted value of 2.65 and lower even than the 2.41 measured for the aqueous PG solution). This indicates that some, as yet unknown, factor besides $S_{\text {org }}$ can substantially influence the co-condensation of SVOCs. Figure 7 shows that good agreement can be achieved between the measured and simulated (black dash line) GF by reducing the mass accommodation coefficient of BG from 1.00 to 0.02 in the model, though there is no reason to expect such a mass transfer limitation in any of the systems investigated.

Using aqueous TEG as the working fluid, the simulated GF (dash line in Fig. 5) for 2 and $4 \mathrm{~m}$ glass reactors was much lower than the measured value. This was the case even when using the same exponential function for $\mathrm{RH}$ and $S_{\text {org }}$ as for the PG simulation. This should lead to an overestimated GF since the volatility of TEG was 275 times lower than PG. A correspondingly slower build-up of the TEG vapour concentration (and hence $S_{\text {org }}$ ) from the reduced evaporation rate should result. Moreover, the simulated GF of larger particles is larger than small ones (as with BG and PG), but the measured GF shows the largest value for $75 \mathrm{~nm}$ dry $\left(\mathrm{NH}_{4}\right)_{2} \mathrm{SO}_{4}$ particles, followed by 100,50 , and $150 \mathrm{~nm}$. This is clearly inconsistent with any of the physical representations in the model, which predict greater growth for the larger particles owing to the Kelvin effect and the controlling influences on the co-condensation of SVOCs are not fully understood.

\subsubsection{Co-condensation of Semi-VOCs with a wide range of volatility}

Whilst the volatility and concentration of each of the organic components (PG, BG, and TEG) used in this study is higher than most of the semi-VOCs in the atmosphere, their saturation ratio is within a reasonable range of those of a wide range of condensable organic components. During the equilibrium growth of a droplet, the absolute magnitude of cocondensation depends on the saturation ratio, $S_{\text {org }}\left(p / p_{0}\right)$, not the absolute values of the vapour pressure ( $p$, reflected by the absolute concentration) nor the saturation vapour pressure ( $p_{0}$, representing the component volatility). By analogy, the hygroscopic growth of particles depends only on $\mathrm{RH}$ $\left(\mathrm{p} / p_{0}\right)$, not the absolute humidity (or water concentration) in the atmosphere. The magnitude of the co-condensation effect will be identical if the same $S_{\text {org }}\left(p / p_{0}\right)$ was sustained for organic compounds of different vapour pressures of low or high volatility.

To illustrate this, the GF profiles with residence time for different volatility organics $\left(\log _{10}\left(\mathrm{C}^{*}\right)\right.$ values $=5.71,5,4$, $3,2,1,0)$ were simulated using ACPIM in Fig. 8. In each simulation in Fig. 8a, the RH and $S_{\text {org }}$ profile was kept the same (i.e. there was no contributing effect on the kinetics of evaporation on the build-up of the gaseous saturation ratio). When $\log _{10}\left(C^{*}\right)$ is decreased from 5.71 to 4 , (i.e. both volatility, $p_{0}$, and concentration, $p$, decrease by a factor of around 51), no difference was observed for GF profile, illustrating how $S_{\text {org }}$ is the controlling factor in the absolute magnitude of co-condensation, not the volatility nor absolute concentration. Below $\log _{10}\left(\mathrm{C}^{*}\right)<4$, the growth is slowed for components with decreasing volatility and the slope of the GF curve decreases with $\log _{10}\left(\mathrm{C}^{*}\right)$ owing to a reduced number of collisions, i.e. longer residence time of lower volatility organic compounds was needed to attain the same final GF. Figure $8 \mathrm{~b}$ illustrates that a more rapid growth can be reestablished by an increase in $S_{\text {org }}$ from 0.1 to 0.5 in the model for relatively low volatility organics $\left(\log _{10}\left(C^{*}\right)=1\right)$ with low concentration $(\sim 0.9 \mathrm{ppb})$. It can be reasonably expected that modest concentrations of organic components can be maintained by various mechanisms in the atmosphere (strong direct sources or in situ oxidative sources, for example) and 

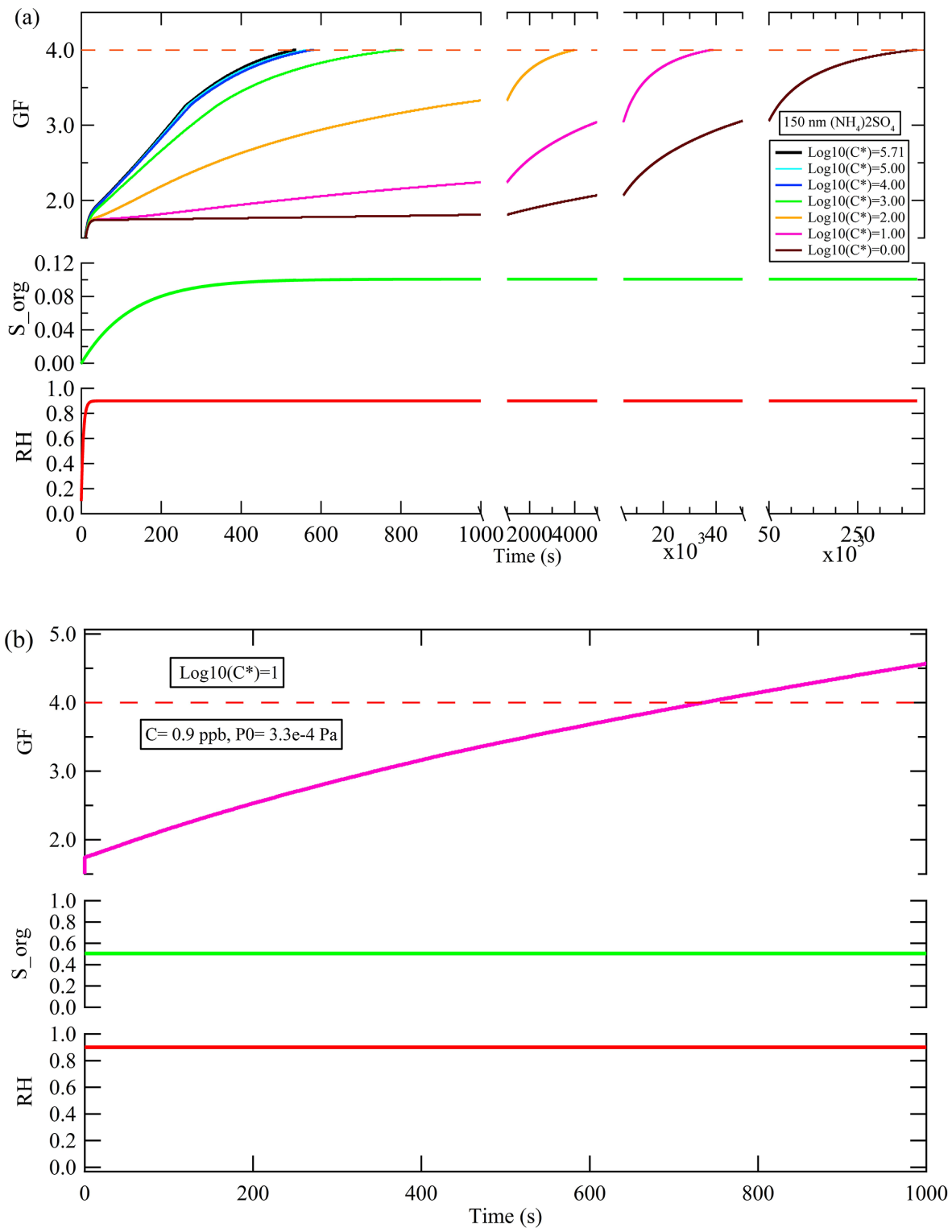

Figure 8. Simulated GF with residence time for (a) organics with a wide range of volatility, keeping the same $S_{\text {org }}$ and RH profile as this study. (b) $\log _{10}\left(\mathrm{C}^{*}\right)=1$ organic, the $S_{\text {org }}$ was increased to 0.5 .

co-condensation effects may be expected to play an important role in the real atmosphere.

\subsection{Uncertainties in the simulated experimental conditions - the influence of axial and radial diffusion effects on the magnitude of co-condensation}

In this study, the bulk velocity $(V)$ was used to calculate the residence time of particles in the glass reactor, and was subsequently used in the ACPIM simulation. In reality, owing to a non-uniform radial velocity profile, particles close to the centerline (wall) in the glass reactor will have a larger (smaller) velocity than $V$, giving these particles a shorter (longer) residence time in the glass reactor, thus achieving a smaller (larger) GF by the condensation of organics and water vapour. To illustrate the possible magnitude of any effect of axial flow heterogeneity, the GF profile with the varying residence time was simulated by ACPIM and the yellow hatched area is bounded by the GF of particles with half or twice the nominal plug flow residence time (Fig. 9a), representing the variation in the axial flow velocity.

Organic vapours in the reactor headspace are diluted by the sample air and scavenged by the co-condensational growth of $\left(\mathrm{NH}_{4}\right)_{2} \mathrm{SO}_{4}$ particles. The growth process proceeds down a stronger concentration gradient at the beginning and be- 

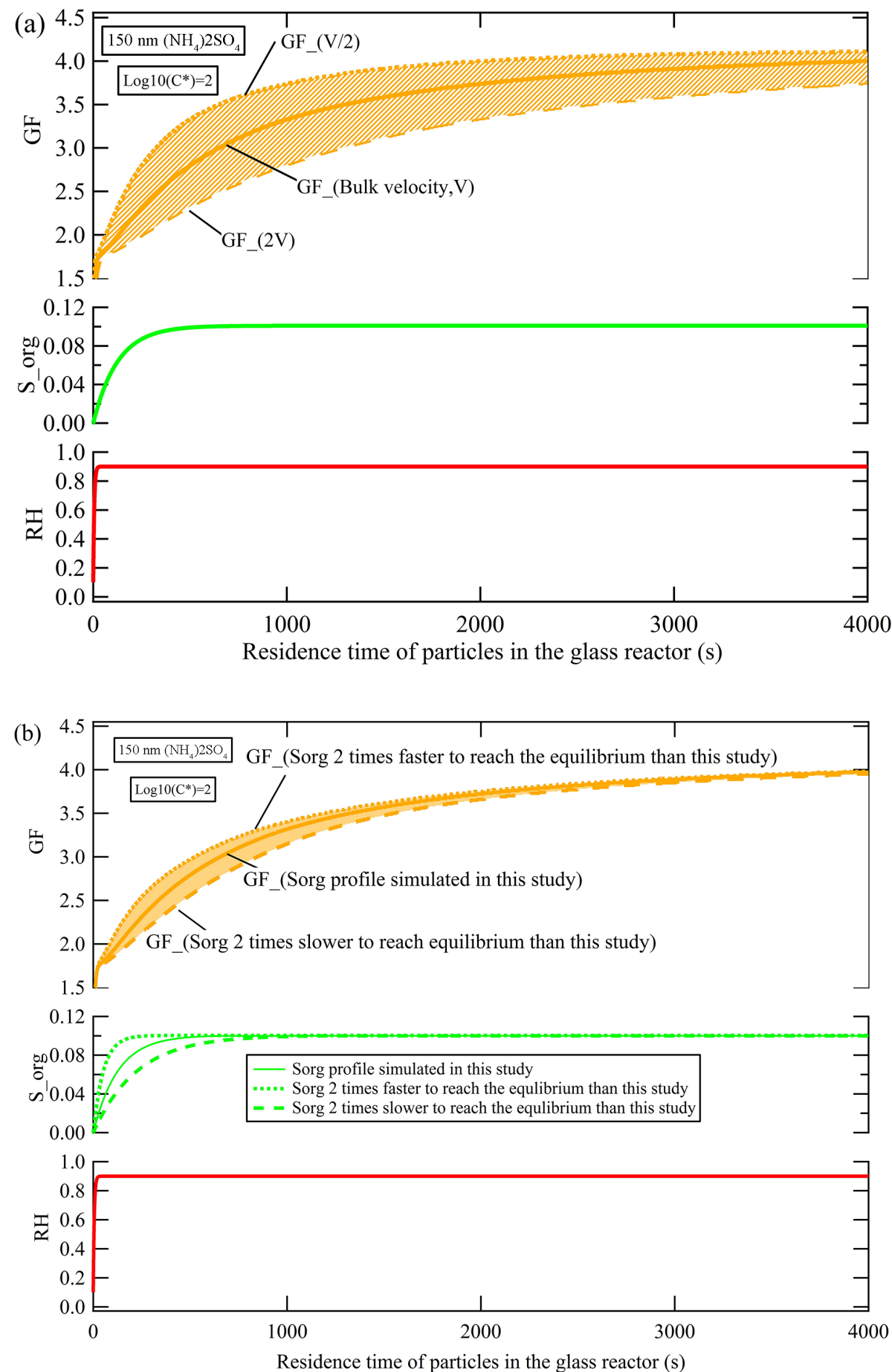

Figure 9. Simulated GF with residence time for organics with $\log _{10}\left(C^{*}\right)=2$ : sensitivity to (a) axial variability and (b) radial variability.

comes weaker with the residence time due to the decrease in vapour pressure difference between the particle surface and the surrounding air. It can be seen from the simulated $S_{\text {org }}$ profile in Figs. 4, 8 and 9 that the organic vapour builds more slowly during the early growth period (first few hundreds of seconds), leading to a radial gradient in $S_{\text {org }}$ dur- ing this period, i.e. the $S_{\text {org }}$ close to the organic solution surface will more rapidly reach equilibrium. Particles passing through different radial positions will experience a different $S_{\text {org }}$ profile. To examine the possible influence of such radial heterogeneity, two GF profile evolution extremes with residence time were simulated by ACPIM for the different $S_{\text {org }}$ 
profiles: one reaching equilibrium twice as fast as in Fig. 4, the other being half as fast. The yellow shading area shows the influence of radial diffusion on the GF profile in Fig. 9b.

It can be seen that, whilst both axial and radial gradients and heterogeneities will exist within our experiments, the generality of our results and conclusions remain largely unaffected.

\section{Implications for the atmosphere}

Our experimental configuration requires that we use a relatively volatile organic compound to maintain its saturation ratio in the vapour phase through evaporation from the solution bath. In the atmosphere, such a limitation will not apply and the saturation ratio may be continuously replenished through surface fluxes or via chemical reaction. A SS is not required and the saturation ratio need only be maintained above the activity in the growing particle. Moreover, in the atmosphere, many thousands of semi-VOCs contribute to the $30-70 \%$ organic mass of the sub-micron aerosol particles (Jimenez et al., 2009; Hallquist et al., 2009) and all can co-condense. This huge diversity of organic components will exhibit a wide range of volatilities and solubilities; nevertheless, the interaction of condensing inorganic or organic components will only ever be to increase a particle's ability to act as CCN under any reasonable assumptions. In Sect. 3.2.3, it is shown that co-condensation of organic components across a wide range of volatility of relevance to the real atmosphere can play a role comparable to that reported in our measurements. Non-ideality and phase separation are complications that will occur in ambient mixtures and must be investigated in order to fully resolve the implications in the atmosphere. However, the exceptional complexity and huge abundance of organic vapours, the fact that they can only enhance water uptake by the measured effect, and the fact that it is an individual component's saturation ratio and not absolute concentration that leads to this effect all mean that the effect of cocondensing organic components cannot be ignored. ACPIM was previously used to show that cloud droplet number in the atmosphere could be enhanced by several tens of percent by co-condensation of organic vapours, with a potential to substantially increase the cooling tendency from a net influence on global albedo (Topping et al., 2013).

Co-condensation of semi-volatile vapours with water during growth in a moist atmosphere and in subsequent cloud droplet formation will substantially challenge conventional instrumentation employing diffusion drying or using thermal gradient to probe $\mathrm{CCN}$ properties. This current study has observed that co-condensation of organic vapours can significantly promote water uptake of aerosol particles, a process which, in the atmosphere, will significantly change particle activation as $\mathrm{CCN}$, cloud droplet growth, and their subsequent influence on indirect radiative forcing.

\section{Conclusions}

Co-condensation of water and organic vapours to $\left(\mathrm{NH}_{4}\right)_{2} \mathrm{SO}_{4}$ particles was directly observed in the laboratory, in an attempt to evaluate the general construct of our theoretical framework. This first study aimed to examine the phenomenon in the most straightforward way, carefully designing the system to avoid complex and largely unquantifiable confounding process-level phenomena such as immiscibility and limited solubility. From our study, we can conclude the following.

Co-condensation of the organic vapours significantly enhances water uptake of aerosols. In this study, the maximum equivalent hygroscopicity parameter, $\kappa$, was observed to reach up to 8.48 , very much higher than values $(0.1<\kappa<0.9)$ measured for atmospheric particulate matter using conventional instrumentation.

Instruments conventionally used to measure particle water uptake will be largely insensitive to, or be unable to quantitatively access, the co-condensation effect. Whilst humidity is controlled in such instruments, initial drying of the sample stream or heating within an instrument will suppress the saturation ratio of organic components by decreasing the organic component mixing ratio or raising the saturation vapour pressure, respectively.

Residence times within such instruments would be too short for them to be sensitive to co-condensation at ambient concentrations of organic components even if they were retained in the instrument.

ACPIM simulation can be tuned to readily reproduce the absolute values of effective hygroscopicity for some systems, but there are factors not considered by the model that play an important role in co-condensation of SVOCs.

Our work should serve as the basis for further investigation, providing the first experimental evidence in this simple system with co-condensation to a single liquid phase. We will aim to include less water-soluble organics in the future, representatively quantifying the impact of liquid-liquid equilibria (LLE) will need to account for a representative spectrum of volatility and solubility such that any result is not sensitive to one particular compound or group of compounds. A possible need to account for the geometry of distinct phases resulting from LLE in cloud activation has been suggested in some studies.

Author contributions. GM and DH designed research; DH performed experiments; DT developed the model code; GM, DT, and DH designed the simulations; DH carried out data analysis; DH performed model simulation; DH, GM, and DT co-wrote the paper.

Data availability. The raw data are available at https://dx.doi.org/ 10.17632/bfwp9p6crm.1. 
The MATLAB code based on the ACPIM model used in Topping et al. (2013) with bespoke modification for the simulation of our experiments is available on request to the authors.

Competing interests. The author declares that there is no conflict of interest.

Acknowledgements. This work was supported through the UK Natural Environment Research Council (NERC) in the CCN-Vol project (grant ref: NE/L007827/1). The infrastructures used within $\mathrm{CCN}-\mathrm{Vol}$ receive funding from the Horizon 2020 research and innovation programme through the EUROCHAMP-2020 Infrastructure Activity under grant agreement no. 730997.

Edited by: Yafang Cheng

Reviewed by: Ari Laaksonen and one anonymous referee

\section{References}

Denman, K. L., Brasseur, G., Chidthaisong, A., Ciais, P., Cox, P. M., Dickinson, R. E., Hauglustaine, D., Heinze, C., Holland, E., Jacob, D., Lohmann, U., Ramachandran, S., da Silva Dias, P. L., Wofsy, S. C., and Zhang, X.: Couplings Between Changes in the Climate System and Biogeochemistry, in: Climate Change 2007: The Physical Science Basis. Contribution of Working Group I to the Fourth Assessment Report of the Intergovernmental Panel on Climate Change, edited by: Solomon, S., Qin, D., Manning, M., Chen, Z., Marquis, M., Averyt, K. B., Tignor, M., and Miller, H. L., 501-587, Cambridge University Press, 2007.

Dusek, U., Frank, G. P., Hildebrandt, L., Curtius, J., Schneider, J., Walter, S., Chand, D., Drewnick, F., Hings, S., Jung, D., Borrmann, S., and Andreae, M. O.: Size matters more than chemistry for cloud-nucleating ability of aerosol particles, Science, 312, 1375-1378, https://doi.org/10.1126/science.1125261, 2006.

Good, N., Coe, H., and McFiggans, G.: Instrumentational operation and analytical methodology for the reconciliation of aerosol water uptake under sub- and supersaturated conditions, Atmos. Meas. Tech., 3, 1241-1254, https://doi.org/10.5194/amt-3-12412010, 2010.

Gysel, M., McFiggans, G. B., and Coe, H.: Inversion of tandem differential mobility analyser (TDMA) measurements, J. Aerosol. Sci., 40, 134-151, https://doi.org/10.1016/j.jaerosci.2008.07.013, 2009.

Hallquist, M., Wenger, J. C., Baltensperger, U., Rudich, Y., Simpson, D., Claeys, M., Dommen, J., Donahue, N. M., George, C., Goldstein, A. H., Hamilton, J. F., Herrmann, H., Hoffmann, T., Iinuma, Y., Jang, M., Jenkin, M. E., Jimenez, J. L., Kiendler-Scharr, A., Maenhaut, W., McFiggans, G., Mentel, Th. F., Monod, A., Prévôt, A. S. H., Seinfeld, J. H., Surratt, J. D., Szmigielski, R., and Wildt, J.: The formation, properties and impact of secondary organic aerosol: current and emerging issues, Atmos. Chem. Phys., 9, 5155- 5236, https://doi.org/10.5194/acp-9-5155-2009, 2009.

Hegg, D. A.: Impact of gas-phase $\mathrm{HNO}_{3}$ and $\mathrm{NH}_{3}$ on microphysical processes in atmospheric clouds, Geophys. Res. Lett., 27, 22012204, https://doi.org/10.1029/1999g1011252, 2000.
Jimenez, J. L., Canagaratna, M. R., Donahue, N. M., Prevot, A. S. H., Zhang, Q., Kroll, J. H., DeCarlo, P. F., Allan, J. D., Coe, H., Ng, N. L., Aiken, A. C., Docherty, K. S., Ulbrich, I. M., Grieshop, A. P., Robinson, A. L., Duplissy, J., Smith, J. D., Wilson, K. R., Lanz, V. A., Hueglin, C., Sun, Y. L., Tian, J., Laaksonen, A., Raatikainen, T., Rautiainen, J., Vaattovaara, P., Ehn, M., Kulmala, M., Tomlinson, J. M., Collins, D. R., Cubison, M. J., Dunlea, E. J., Huffman, J. A., Onasch, T. B., Alfarra, M. R., Williams, P. I., Bower, K., Kondo, Y., Schneider, J., Drewnick, F., Borrmann, S., Weimer, S., Demerjian, K., Salcedo, D., Cottrell, L., Griffin, R., Takami, A., Miyoshi, T., Hatakeyama, S., Shimono, A., Sun, J. Y., Zhang, Y. M., Dzepina, K., Kimmel, J. R., Sueper, D., Jayne, J. T., Herndon, S. C., Trimborn, A. M., Williams, L. R., Wood, E. C., Middlebrook, A. M., Kolb, C. E., Baltensperger, U., and Worsnop, D. R.: Evolution of Organic Aerosols in the Atmosphere, Science, 326, 1525-1529, https://doi.org/10.1126/science.1180353, 2009.

Köhler, H.: The nucleus in and the growth of hygroscopic droplets, T. Faraday Soc., 32, 1152-1161, https://doi.org/10.1039/tf9363201152, 1936.

Kulmala, M., Laaksonen, A., Korhonen, P., Vesala, T., Ahonen, T., and Barrett, J. C.: The effect of atmospheric nitric-acid vapor on cloud condensation nucleus activation, J. Geophys. Res., 98, 22949-22958, https://doi.org/10.1029/93jd02070, 1993.

Kulmala, M., Laaksonen, A., Charlson, R. J., and Korhonen, P.: Clouds without supersaturation, Nature, 388, 336-337, https://doi.org/10.1038/41000, 1997.

Laaksonen, A., Korhonen, P., Kulmala, M., and Charlson, R. J.: Modification of the Köhler equation to include soluble trace gases and slightly soluble substances, J. Atmos. Sci., 55, 853-862, https://doi.org/10.1175/15200469(1998)055<0853:motkhe>2.0.co;2, 1998.

McFiggans, G., Artaxo, P., Baltensperger, U., Coe, H., Facchini, M. C., Feingold, G., Fuzzi, S., Gysel, M., Laaksonen, A., Lohmann, U., Mentel, T. F., Murphy, D. M., O’Dowd, C. D., Snider, J. R., and Weingartner, E.: The effect of physical and chemical aerosol properties on warm cloud droplet activation, Atmos. Chem. Phys., 6, 2593-2649, https://doi.org/10.5194/acp-6-25932006, 2006.

McFiggans, G., Topping, D. O., and Barley, M. H.: The sensitivity of secondary organic aerosol component partitioning to the predictions of component properties - Part 1: A systematic evaluation of some available estimation techniques, Atmos. Chem. Phys., 10, 10255-10272, https://doi.org/10.5194/acp-10-102552010, 2010.

Romakkaniemi, S., Kokkola, H., and Laaksonen, A.: Parameterization of the nitric acid effect on $\mathrm{CCN}$ activation, Atmos. Chem. Phys., 5, 879-885, https://doi.org/10.5194/acp-5-8792005, 2005.

Romakkaniemi, S., Jaatinen, A., Laaksonen, A., Nenes, A., and Raatikainen, T.: Ammonium nitrate evaporation and nitric acid condensation in DMT CCN counters, Atmos. Meas. Tech., 7, 1377-1384, https://doi.org/10.5194/amt-7-1377-2014, 2014.

Rudolf, R., Majerowicz, A., Kulmala, M., Vesala, T., Viisanen, Y., and Wagner, P. E.: Kinetics of particle growth in supersaturated binary vapor mixtures, J. Aerosol Sci., 22, S51-S54, https://doi.org/10.1016/s0021-8502(05)80032-1, 1991.

Rudolf, R., Vrtala, A., Kulmala, M., Vesala, T., Viisanen, Y., and Wagner, P. E.: Experimental study of sticking probabil- 
ities for condensation of nitric acid-water vapor mixtures, J. Aerosol Sci., 32, 913-932, https://doi.org/10.1016/s00218502(00)00117-8, 2001.

Topping, D., Connolly, P., and McFiggans, G.: Cloud droplet number enhanced by co-condensation of organic vapours, Nat. Geosci., 6, 443-446, https://doi.org/10.1038/ngeo1809, 2013.

Topping, D. O. and McFiggans, G.: Tight coupling of particle size, number and composition in atmospheric cloud droplet activation, Atmos. Chem. Phys., 12, 3253-3260, https://doi.org/10.5194/acp-12-3253-2012, 2012.
Xue, H. W. and Feingold, G.: A modeling study of the effect of nitric acid on cloud properties, J. Geophys. Res., 109, D18204, https://doi.org/10.1029/2004jd004750, 2004. 